\title{
Selection of biomass supply for a gasification process in a solar thermal hybrid plant for the production of electricity
}

\author{
M. Guadalupe Pinna-Hernández ${ }^{\mathrm{a}, \mathrm{b}, *}$, Ignacio Martínez-Soler ${ }^{\mathrm{c}}$, Manuel J. Díaz Villanueva ${ }^{\mathrm{d}}$, \\ Francisco G. Acien Fernández ${ }^{c}$, José Luis Casas López ${ }^{\mathrm{a}, \mathrm{b}}$ \\ a Department of Chemical Engineering, University of Almería, Carretera de Sacramento s/n, 04120 La Cañada de San Urbano, Spain \\ ${ }^{\mathrm{b}}$ Solar Energy Research Centre (CIESOL), Joint Centre University of Almería-CIEMAT, Almería, 04120, Spain \\ ${ }^{\mathrm{c}}$ Marine Microalgae Biotechnology Research Group, University of Almería, Carretera de Sacramento s/n, 04120 La Cañada de San Urbano, Almería, Spain \\ ${ }^{\mathrm{d}}$ Department of Chemical, Environmental and Materials Engineering, Center for Advanced Studies in Energy and Environment (CEAEMA), University of Jaen, Campus las \\ Lagunillas, 23071 Jaén, Spain
}

\section{A R T I C L E I N F O}

\section{Keywords:}

Biomass

Almond shells

Olive tree prunings

Holm oak prunings

Greenhouse vegetable residues

Solar thermal hybridization

\begin{abstract}
A B S T R A C T
The great potential for bioenergy in Spain is undeniable given our country's enormous biomass supply. This fact contrasts with the limited evolution in the biomass sector for thermal and electricity generation over recent years. In this paper, we consider the utilization of fluidized bed gasification (FBG) as a biomass utilization technology incorporated into a thermal electric system to improve power plant production both thermally and electrically. Firstly, we studied the biomass resources available within a $100 \mathrm{~km}$ radius of the plant's location in Almería province (Spain). This biomass included almond shells, olive tree prunings, holm oak prunings and vegetable residues from greenhouse tomato and pepper plants. Technical criteria were applied to determine the most appropriate biomass to use in the gasification process; this included the physical-chemical characterization, the cost and the logistic-agronomic profile. The physical-chemical characterization included humidity, ash, calorific value, an elemental analysis, sulfur and chlorine, etc. On the basis of this characterization, almond shells were found to be the optimal biomass $\left(\mathrm{M}_{\mathrm{ar}}=12.9 \%, \mathrm{~A}_{\mathrm{r}}=1.1 \%, \mathrm{~V}_{\mathrm{d}}=82.2 \%, \mathrm{Q}_{\mathrm{p}, \text { net,d }}=18,470 \mathrm{~kJ} / \mathrm{kg}\right.$ and $\mathrm{Cl}=60 \mathrm{mg} / \mathrm{kg}$ ), and depending on certain parameters, could be classified as A1 or A2. Both the olive tree prunings $\left(\mathrm{M}_{\mathrm{ar}}=6.2 \%, \mathrm{~A}_{\mathrm{r}}=5.5 \%, \mathrm{Vd}=83.4 \%, \mathrm{Q}_{\mathrm{p}, \mathrm{net}, \mathrm{d}}=18,193 \mathrm{~kJ} / \mathrm{kg}\right.$ and $\left.\mathrm{Cl}=15 \mathrm{mg} / \mathrm{kg}\right)$ and the holm oak prunings $\left(\mathrm{M}_{\mathrm{ar}}=9.2 \%, \mathrm{~A}_{\mathrm{r}}=4.1 \%, \mathrm{~V}_{\mathrm{d}}=80.3 \%, \mathrm{Q}_{\mathrm{p}, \text { net, } \mathrm{d}}=16,335 \mathrm{~kJ} / \mathrm{kg}\right.$ and $\left.\mathrm{Cl}=12 \mathrm{mg} / \mathrm{kg}\right)$ were also considered to be good biomass resources, and were given an A2 or B1 classification. However, greenhouse vegetable residues (tomato and pepper) did not have suitable technical parameters $\left(\mathrm{M}_{\mathrm{ar}}=82.6-29.6 \%, \mathrm{~A}_{\mathrm{r}}=35.5-6.4 \%\right.$, $\mathrm{V}_{\mathrm{d}}=75.1-59.1 \%, \mathrm{Q}_{\mathrm{p}, \text { net,d }}=17277-11529 \mathrm{~kJ} / \mathrm{kg}$ and $\mathrm{Cl}=1196-751 \mathrm{mg} / \mathrm{kg}$ ) for use in the gasification process. Concerning the economic criteria, the best cost per kilogram $(0.01 € / \mathrm{kg})$ was found for the greenhouse vegetable residues, followed by the olive tree prunings $(0.04 € / \mathrm{kg})$; the highest cost corresponded to almond shells $(0.07 € /$ $\mathrm{kg}$ ). With regard to the logistic-agronomic criteria, the theoretical hours of production in the power station are determined by the total availability of the resource in the particular location. The results indicate that the amount of almond shells available in the area was not sufficient $(3854 \mathrm{~h}$ ) to ensure the operation of the power station at full load $(8760 \mathrm{~h})$ but it would be possible in conjunction with other biomass types. The final decision regarding the optimal biomass to use was made on the basis of a multivariable analysis using the Visual Preference Ranking Organization Methods for Enrichment Evaluations (PROMETHEE) tool. From this analysis, olive tree prunings were selected as the optimum biomass to use because of their extensive local availability $(58,080 \mathrm{t} /$ year $)$, in addition to them having suitable physical-chemical characteristics $\left(\mathrm{M}_{\mathrm{ar}}=6.2 \%, \mathrm{~A}_{\mathrm{r}}=5.5 \%\right.$, $\mathrm{V}_{\mathrm{d}}=83.4 \%, \mathrm{Q}_{\mathrm{p}, \text { net,d }}=18,193 \mathrm{~kJ} / \mathrm{kg}$ and $\left.\mathrm{Cl}=15 \mathrm{mg} / \mathrm{kg}\right)$ ) and a reasonable cost $(0.07 € / \mathrm{kg})$.
\end{abstract}

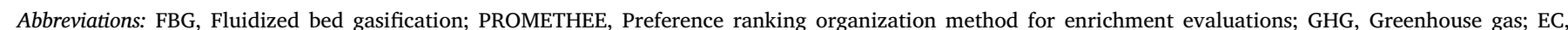

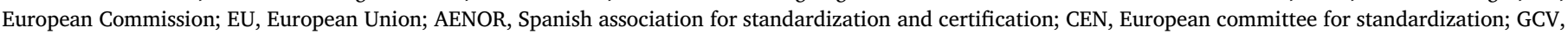
Gross calorific value; CV, Calorific value; NCV, Net calorific value; GAIA, Geometrical analysis for interactive

* Corresponding author.

E-mail address: gpinnahernandez@ual.es (M.G. Pinna-Hernández). 


\section{Introduction}

Climate change is mainly being generated by the increase in greenhouse gas (GHG) emissions caused by human activities such as the use of fossil fuels (in daily life or in industrial development) and the decomposition of urban or agrarian wastes. Although the European Commission (EC) has been working on this issue since the beginning of the 1980 's, there is still a long way to go before we can effectively reduce GHG concentrations - the most important of which (from a negative impact perspective) are: $\mathrm{CO}, \mathrm{CO}_{2}, \mathrm{SO}_{\mathrm{x}}, \mathrm{NO}_{\mathrm{x}}, \mathrm{VOC}, \mathrm{O}_{3}$, heavy metals ( $\mathrm{Pb}, \mathrm{Hg}, \mathrm{Cu}, \mathrm{Cd}, \mathrm{Zn}$ ) and radionuclides (Kiely, 2003).

Considering the role of a sustainable energy policy to achieve climate objectives, the European Council adopted the Action Plan of the European Council 2007-2009 at the 2007 Spring Summit - the energy policy was based on three principles: security of supply, efficiency and environmental compatibility. At the summit, it was agreed to: reduce the use of primary energy ( $20 \%$ by 2020 ), expand the percentage of renewable energy in the primary energy structure to $20 \%$ by 2020 and to reduce GHG emissions throughout the European Union (EU) at least $20 \%$ by 2020 (compared to 1999 levels).

To meet these objectives, natural resources are available that contribute substantially to the development and implementation of renewable energies as a whole: solar radiation, wind, biomass, marine currents and terrestrial heat, amongst others. These sources, through their corresponding technology, generate different forms of energy that are applicable in diverse fields: solar energy (solar thermal energy and photovoltaic solar energy), wind energy, biomass energy, marine energy and geothermal. Currently, renewable energies represent $13.4 \%$ of the total energy consumed worldwide and biofuels and waste represent about 9.4\% (International Energy Agency, 2017); in the EU, this amounts to about $4.4 \%$ of the total primary energy (European biomass association, 2017). Focusing on the data for Andalusia, renewable energies remain prominent in the energy consumption matrix. In 2016, consumption increased by $325.2 \mathrm{ktep}$, reaching a total contribution of 3497.7 ktep. This increase was mainly driven by the higher biomass consumption from the olive oil industry and the higher electricity generation from solar thermal and wind energy (Andalusian Agency of Energy, 2016). Finally, the data for Almería, where the solar thermal energy hybrid plant under consideration is located, indicate that, in terms of final energy consumption (Andalusian Agency of Energy, 2016), about $4 \%$ represents biomass and around $0.6 \%$ is solar thermal.

Solar thermal energy technologies can significantly contribute to addressing these two issues, helping to mitigate the impact of electricity generation on GHG whilst providing a sustainable and balanced growth path for the supply of affordable electricity in both industrialized and developing countries. A carbon-free generation system can only be achieved with renewable technologies that are dispatchable, and resource and technological considerations point to solar thermal energy plants as the best potential alternative for meeting the world's growing energy needs. They are also the alternative for providing the largest fraction of value from local sources, even for the very first plant built. "Local value added" considerations may well be a key factor in policy decision-making for many countries. The three main arguments for the large-scale deployment of solar thermal energy plants are: dispachability and other technical features, the macroeconomic impact on local economies and competitiveness (European Solar Thermal Electricity Association, 2012).

Solar radiation is a discontinuous renewable resource. Therefore, to guarantee a continuous production supply of solar thermal energy, a storage or hybridization system has to be considered, thus affecting plant management. In the plant layout discussed in this paper, we consider solar thermal energy generation hybridized with a biomass-fed gasification process, which will offer the following advantages over a conventional solar thermal energy plant: improving the overall annual net performance of the plant, avoiding stop/starts of the solar installation's turbine, improving manageability, reducing or eliminating storage needs, reducing the dimensions of the solar field, improving the equipment amortization, increasing the plant's annual capacity, and making it possible to have a $100 \%$ renewable operation, so reducing $\mathrm{CO}_{2}$ emissions (María Guadalupe Pinna Hernández, 2017). As regards the biomass, it is essential to know its physical, chemical and energetic characteristics to be able to use it efficiently thus ensuring the greatest possible energy use. This issue is regulated both nationally and internationally, with specific rules allowing us to determine the quality of the different parameters and how they may be used in different technologies. The biomass conversion technologies for electricity and thermal energy that are currently viable in Spain are combustion, gasification and biodigestion.

This work studies five possible biomass resources for their use in a gasification process hybridized to solar thermal energy. The selected biomasses are: almond shells, olive tree prunings, holm oak prunings, and tomato and pepper greenhouse residues. Three criteria were considered for the study: technical - this aspect was given greater weight and considered the different parameter values obtained from the physical-chemical analysis; economic - this carried less weight than the technical criterion but more than the logistic-agronomic criterion; the latter considered the production of each biomass to calculate the plant's theoretical production hours. For the final decision-making step, we considered different variables with different weights, meaning we had to perform a multivariate analysis using the Visual-PROMETHEE tool.

\section{Materials and methods}

\subsection{Biomass types}

The following types of biomass were studied: almond shells, olive tree prunings (mainly branches), holm oak tree prunings and greenhouse vegetable residues (tomato and pepper - no fruit and raffia-free). They were chosen because they are available in the geographical area surrounding the solar-thermal hybrid power plant (within a 100-kilometer radius), and because of their known technical capabilities. The biomasses considered did not undergo any pretreatment.

\subsection{Biomass characterization}

It should be pointed out that the tests were performed in accordance with the Spanish association for standardization and certification (AENOR in Spanish), as shown in Table 1. It is important to rely on specific standards in determining the quality parameters of the solid biofuels, not only for the differences between each of them, but also with regards to fossil fuels (coal, coke, natural gas, and oil). Currently, there is a specific methodology for characterizing solid biofuels overseen by the European Committee for Standardization (CEN). This institution sets the standards for characterizing each of the solid biofuel parameters at the European level. Each European country, through its corresponding national associations, interprets and adapts these rules for use in its own territory. In Spain, AENOR is responsible for preparing and applying these regulations and methodologies through its corresponding technical standardization committee (CTN 164 Solid Biofuels).

\subsubsection{Moisture, ash and volatile matter}

The determination of the total moisture content was performed by drying the biomass in an oven at a temperature of $105( \pm 2){ }^{\circ} \mathrm{C}$, with a complete exchange of air 3 to 5 -times per hour. The moisture percentage was calculated by the mass of the sample and taking into account the variation of the mass of the trays used by the dilation produced from the heat. The particle size of the biofuel to be analyzed must be less than $30 \mathrm{~mm}$ and the mass of the sample must be at least $300 \mathrm{~g}$ for the performance of this test. It is important to weigh an empty tray identical to the tray in which the sample is placed (reference tray) to perform a buoyancy correction. Finally, the loss of mass that can be 
Table 1

The biomass quality parameter standards followed and the measurement equipment used.

\begin{tabular}{lll}
\hline Parameters & Standards & Measuring equipment \\
\hline Moisture (\%) & EN 14774-1 & Drying Oven (Memmert UFE 700) \\
Ash (\%) & EN 14775 & Muffle Furnace (NABERTHERM LVT 15/11) \\
Volatile matter (\%) & EN 15148 & Muffle Furnace (NABERTHERM LVT 15/11) \\
Calorific value (MJ/kg) & EN 14918 & Calorimeter (Parr 6300) \\
Elementary analysis, CHN (\%) & EN 15104 & Analyzer (LECO TruSpec CHN 620-100-400) \\
Chlorine (mg/kg) & EN 15289 & Automatic potentiometer (Mettler Toledo G20 Titrator) \\
Sulphur $(\%)$ & EN 15289 & Analyzer (LECO TruSpec CHN 620-100-400) \\
Major elements $(\mathrm{mg} / \mathrm{kg})$ & EN 15290 & ICP OES VARIAN 715-ES \\
Minor elements $(\mathrm{mg} / \mathrm{kg})$ & EN 15297 & ICP OES VARIAN 715-ES \\
Bulk density $\left(\mathrm{kg} / \mathrm{m}^{3}\right)$ & EN 15103 & Standarized container \\
Granulometry & EN 15149-2 & Granulometry/Laboratory Sieve Shaker (Restch AS 400) \\
Fusibility & CEN/TS 15370-1 & Analyzer (LECO TruSpec CHN 620-100-400) \\
\hline
\end{tabular}

observed in the container or bag that contained the sample due to moisture that may have been transferred to it is taken into account.

The moisture content, $\mathrm{M}_{\mathrm{ar}}$, of the biofuel, expressed as a percentage of mass, is calculated using equation (1):

$M_{a r}=\frac{\left(m_{2}-m_{3}\right)-\left(m_{4}-m_{5}\right)+m_{6}}{\left(m_{2}-m_{1}\right)+m_{6}} \times 100$

Moisture decreases the biofuel's gross calorific value (GCV) and can also cause problems such as condensate in the boiler flues, fermentation in the biomass storage systems and the development of fungi and moulds that might potentially cause inhalation problems.

The ash content is determined by calculating the mass of the residue remaining after the sample has been heated in air under controlled conditions of time, sample weight and equipment specifications, at a regulated temperature of $550( \pm 10){ }^{\circ} \mathrm{C}$. Plates or crucibles made of ceramic material, silica or platinum, are heated empty at $550{ }^{\circ} \mathrm{C}$ for at least an hour to eliminate any possible impurities they may contain. Once cold, the milled biofuel sample is added (less than $1 \mathrm{~mm}$ ) and heated in the oven, evenly raising the temperature to $250{ }^{\circ} \mathrm{C}$ over 30 50 minutes (i.e. a $4.5{ }^{\circ} \mathrm{C} / \mathrm{min}$ heat ramp at $7.5^{\circ} \mathrm{C} / \mathrm{min}$ ). Once reached, this temperature is maintained for $60 \mathrm{~min}$ to allow the volatiles to evaporate before ignition. Subsequently, the temperature is continuously increased to $550( \pm 10)^{\circ} \mathrm{C}$ for $30 \mathrm{~min}$ (a heat ramp of $10^{\circ} \mathrm{C}$ / $\mathrm{min}$ ) and this temperature is maintained for $120 \mathrm{~min}$. Finally, the crucibles are cooled in a desiccator cabinet and weighed. The sample's dry base ash content, $A_{d}$, expressed as a percentage of mass (on a dry basis) is calculated with equation (2):

$A_{d}=\frac{m_{3}-m_{1}}{m_{2}-m_{1}} \times 100 \times \frac{100}{100-M_{a d}}$

A good biofuel generates little ash since a high ash content involves more cleaning and maintenance of the heating device and can also cause problems in the deposits, slag, etc. A high ash content may be because the biomass contains an elevated innate inorganic component or that it is contaminated with other products such as sand or earth, present because of an incorrect collection process.

Finally, as ash contains all the biofuel's inorganic and metallic components, having a high ash content increases the probability of corrosion processes in the boiler if proper maintenance is not carried out. The volatile content is determined from the residue that remains in a closed crucible after being placed in a muffle furnace for $7 \mathrm{~min}$ at a temperature of $900( \pm 10){ }^{\circ} \mathrm{C}$. The sample's volatile matter content, $\mathrm{V}_{\mathrm{d}}$, expressed as a percentage of mass on a dry basis, is calculated using equation (3):

$V_{d}=\left[\frac{100 \times\left(m_{2}-m_{3}\right)}{m_{2}-m_{1}}-M_{a d}\right] \times\left(\frac{100}{100-M_{a d}}\right)$

The volatile fraction is the part of the biomass that volatilizes easily, burning in combination with oxygen. Biomass with a small volatile content has a lower GCV and non-burning problems, usually requiring a higher temperature in the combustion process, meaning greater energy expenditure.

\subsubsection{Gross calorific value, bulk density and energetic density}

To calculate the calorific value (CV), one must first determine the GCV of a solid biofuel at a constant volume and at a temperature of $25^{\circ} \mathrm{C}$, using a calorimetric pump calibrated by combusting certified benzoic acid. The result obtained is the GCV at a constant volume, with all the water from the combustion products in the form of liquid water. In practice, biofuels are burned at a constant pressure (atmospheric) and the water is either removed with the exhaust gases as steam, or condensed. Under both conditions, the actual heat released in the combustion is the fuel's net calorific value (NCV) measured at constant pressure, which can be calculated from the following equation (4) using the GCV at constant volume and the elemental analysis.

$Q_{p, n e t, d}=q_{v, g r, d}-212.2 \times H_{A}-0.8 \times\left(O_{A}-N_{A}\right)$

The bulk density determination consists of weighing a test portion placed in a container of a standard size and volume. Bulk density is calculated from the net weight per standardized volume and is accompanied by the moisture result. If this is combined with the CV calculation, the energy density parameter can be obtained. Bulk density is an important volume-based parameter for fuel supplies, which determines the biofuel's storage space and transport needs.

\subsubsection{Elementary analysis, chlorine and sulphur, and major and minor elements}

To perform the elemental analysis, a quantity of sample mass is burnt in the presence of oxygen, or in a mixture of oxygen/carrier gas, under conditions that will convert it to ash and gaseous combustion products (carbon dioxide, steam (of water), elemental nitrogen and/or nitrogen oxides, oxides and oxyacids of sulphur, and hydrogen halides). The combustion products are treated to ensure that any hydrogen not associated with the sulphur or halide combustion products is released as water vapor. Nitrogen oxides are reduced to elemental nitrogen and those combustion products that would interfere with the subsequent gas analysis procedures are eliminated. Then, the mass fractions of carbon dioxide, water vapor and nitrogen in the gas stream are determined quantitatively using instrumental techniques. In this case, after the correction was made with standard EDTA, a sample amount of between 0.1 and $0.25 \mathrm{~g}$ was combusted in the instrumental equipment at $950{ }^{\circ} \mathrm{C}$, and the proportion of carbon, hydrogen and nitrogen was quantified using the detection analyzer.

Reliable carbon, hydrogen and nitrogen determination is important for quality control and for calculating the NCV. Likewise, the environmental importance of the nitrogen content is relevant for $\mathrm{NO}_{\mathrm{x}}$ emissions whilst the carbon determines the $\mathrm{CO}_{2}$ emissions.

For the determination of chlorines, calorimetric pump digestion was chosen to measure the CV in accordance with the UNE-EN 14918: 2011 Standard. These chlorines, which are collected in the washing waters 
generated during combustion, are measured with silver nitrate using potentiometry. In the case of sulphur, we used high-temperature combustion $\left(1350^{\circ} \mathrm{C}\right)$ in a tubular furnace, quantifying the gaseous combustion products that were formed (similar to the quantification of the total carbon, hydrogen and nitrogen content). Chlorine and sulphur are present in solid biofuels at varying concentrations; during the combustion process, they are usually converted into sulphur oxides and chlorides. The presence of these elements, and their reaction products, can contribute significantly to heating equipment corrosion and the emission of harmful compounds into the environment, in the form of $\mathrm{SO}_{\mathrm{x}}$.

The determination of the main elements and their ashes, such as $\mathrm{Al}$, $\mathrm{Ca}, \mathrm{Fe}, \mathrm{Mg}, \mathrm{P}, \mathrm{K}, \mathrm{Si}, \mathrm{Na}$ and $\mathrm{Ti}$, was carried out through digestion in a closed fluoropolymer container, using nitric acid, hydrogen peroxide and hydrofluoric acid in a microwave oven at a controlled temperature and pressure. The digestion was carried out directly on the biofuel, or in an ash preparation, at $550{ }^{\circ} \mathrm{C}$. Element detection can be done using ICPOES. The main elements described of the solid biofuels are, in fact, the main elements of the fuel ashes rather than the fuel. The determination of these elements can be used to evaluate the ashes' behavior in a thermal conversion process or to evaluate their potential use, mainly as fertilizer. Conversely, the determination can be used as an indicator of biofuel contamination since high values of several elements might be caused by contamination from sand, earth, paints or other additives; therefore, it is important to control the concentration of these elements because, in certain chemical and environmental situations, they can cause corrosion inside the heating appliances.

We considered the minor elements present in the solid biofuels: As, $\mathrm{Cd}, \mathrm{Co}, \mathrm{Cr}, \mathrm{Cu}, \mathrm{Hg}, \mathrm{Mn}, \mathrm{Mo}, \mathrm{Ni}, \mathrm{Pb}, \mathrm{Sb}, \mathrm{V}$ and $\mathrm{Zn}$. The sample used to perform the analysis was digested in the same way as for the determination of the major elements but with different concentrations of reactants and different temperature ranges. The quantification was performed as with the other technique. The minor elements in solid biofuels were determined mainly for environmental reasons. It has been shown that certain energy crops concentrate certain elements such as Cd in the field, which can prove harmful.

\subsection{Multicriteria selection}

In order to describe a real-life situation, several simultaneous variables are required that condition it to a greater or lesser extent. However, to understand the relationships between the different variables, a data analysis must be performed - a multivariate analysis, which is a statistical study of several variables measured in elements of a population. To carry out this analysis, we used the Visual PROMETHEE Academic Edition tool, which is Multiple Criteria Decision Aid software and it is the last and the most complete and up to-date software implementation of the PROMETHEA and GAIA multicriteria decision aid. It is designed to help evaluate several possible decisions or items according to multiple and often conflicting criteria, identify the best possible decision, rank possible decisions from best to worst, sort items into predefined classes, visualize decision or evaluation problems to better understand the difficulties in making good decisions, and achieve consensus decisions when several decision-makers have conflicting points of view by justifying or invalidating decisions based on objective elements.

This work has used the following capacities of PROMETHEE and GAIA: intuitive and comprehensive spreadsheet interface and GAIA Visual Analysis where has been obtained visual weight sensitivity analyses and the results are analyzed in point 3.5. multicriterioa selection.

The multicriteria analysis considered biomasses from almond shells, olive tree prunings, holm oak prunings and greenhouse vegetable residues from tomato and pepper plants. The criteria determining the choice of biomass are technical, economic and logistic-agronomic. The technical criteria are given greater weight, followed by the economic and then the logistic-agronomic criteria. With regard to the criteria determination for each biomass, technicians consider whether or not to use minimum technical conditions in the gasification process as well as economic and logistic-agronomic conditions that are evaluated into five different levels.

\section{Results and discussion}

\subsection{Boundary conditions for the selection of the biomass type}

The power plant considered is a solar thermal energy hybrid with parabolic trough concentrated solar energy technology hybridized with a biomass exploitation process. Studied in detail, combustion was discarded prior to the gasification process since with the combustion it cannot be considered the route of electrical utilization in front of the gasification that would considered for both thermal and electrical use (María Guadalupe Pinna Hernández, 2017). Looking more deeply at the different types of gasification, we considered: countercurrent mobile bed, moving bed in parallel and fluidized bed, finally choosing the FBG process because the electrical power required for the plant $\left(1 \mathrm{MW}_{\mathrm{e}}\right)$, would allow good performance at partial or total load with proven profitability, simplicity, flexibility and robustness, as analyzed and described previously (Gómez-Barea and Leckner, 2010). The technical capabilities of the solar thermal energy hybrid plant are: a $1 \mathrm{MW}_{\mathrm{e}}$ electrical power output from the power station and the gasifier, respectively; in-parallel integration with the solar field, and via coupling, the added possibility of in-series operation with the solar field, as well as with components of the power plant (the solar field, exchanger, power block, steam turbine, boiler and auxiliary systems) and with the heat transfer fluid (the thermal oil). Regarding the mode of operation chosen to operate the plant, this decision is dependent on the biomass requirements, and with it, its viability. The main aim of the study is to obtain a total load operation of the thermoelectric plant during the day and a total gasifier load at night.

The correct choice of biomass resource for the FBG process inside the solar thermal electricity hybrid plant is crucial to obtain optimal results, both from the technical and economic points of view. The factors that need to be taken into account to select a potential biomass are: technical - namely, the physical-chemical characteristics of the biomass; agronomic - determining the areas to cultivate and the biomass production generated annually; and finally the approximate cost. The biomass resources considered were: almond shells, olive tree prunings, holm oak prunings, and greenhouse vegetable residues from tomato and pepper plants.

The solar thermal energy hybrid plant considered in this study is located in Tabernas, a municipality in the province of Almería (Andalusia), situated in the Filabres-Tabernas region at an altitude of $400 \mathrm{~m}$ above sea level, and $29 \mathrm{~km}$ from the provincial capital, Almería. This location is excellent for two main reasons, the direct normal irradiance at the site is $2059 \mathrm{kWh} / \mathrm{m}^{2}$ (Ministry of Agriculture and Fisheries, 2014) and it is surrounded by multiple hectares of crops capable of generating different types of biomass for the combustion process; these are detailed in the agronomic analysis.

\subsection{Biomass characterization}

The energetic properties of the different biomasses were determined using the official methods established by CEN and the results are shown in Table 2. Samples were characterized by their dry weight content. The oxygen content was calculated as the difference between 100 and the sum of carbon, hydrogen, nitrogen, sulphur, chlorine and the ash content. The NCV was calculated based on the information of analysis and the GCV experimental values.

\subsubsection{Moisture, ash and volatile matter}

The moisture from the biomass samples analyzed was between $6.2 \%$ 
Table 2

Technical parameters of the energetic analysis.

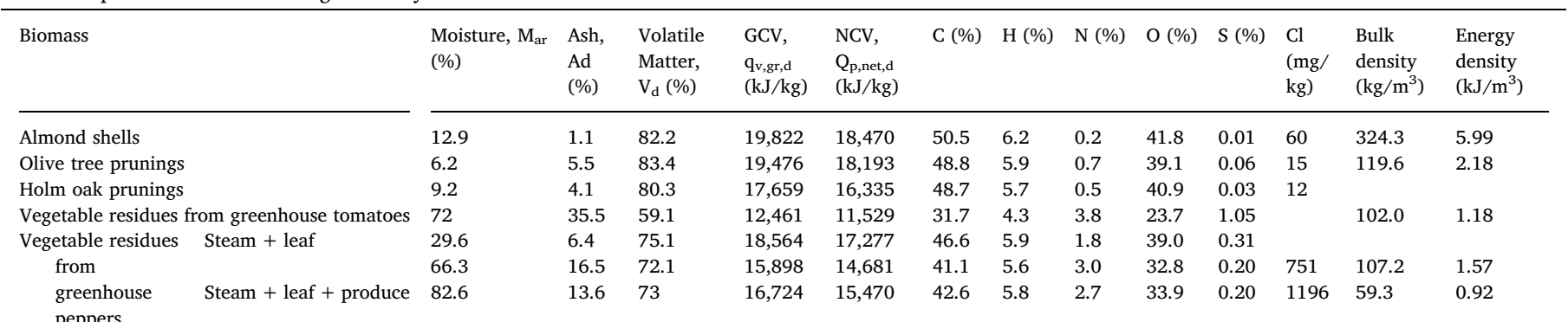

and $82.6 \%$, corresponding to the lowest values for almond shells, olive tree prunings and holm oak prunings, and the highest values for the greenhouse residues. The moisture level is important during thermochemical conversion (gasification) as heat must be supplied to remove the water from the feedstock. The latent heat of evaporation of water is $2.305 \mathrm{MJ} / \mathrm{kg}$ at $25^{\circ} \mathrm{C}$ (Wang, 2008). A similar trend could be observed in the ash content, with almond shells being the biomass with the lowest ash content of those studied, at $1.1 \%$, while vegetable residues from tomato plants had an ash content of $35.5 \%$. In the case of almond shells and holm oak prunings, the values obtained were slightly lower than those found by others authors (García et al., 2012), while for olive tree prunings, the ash measurement was slightly higher than expected (Díaz et al., 2011). In woody biomass, the variations in ash content might be due to the presence of bark (AENOR, 2014a). In the case of the greenhouse residues studied, the ash values differed from those found in the bibliography (García et al., 2012), which may be due to external contamination from soil or sand due to cutting and harvesting activities (AENOR, 2014a). For the thermochemical conversion of agricultural residues with high ash contents, consideration must be given to incorporating efficient ash removal equipment for the flue gas in order to eliminate or reduce particulate pollution (Werther et al., 2000); this fact has not been considered in our article.

Agricultural residues are characterized by higher volatile matter contents (Vassilev et al., 2010), and this was confirmed in all the samples analyzed with values above 59\% - indicating that the residues are easier to ignite and to convert thermochemically.

\subsubsection{Gross calorific value, bulk density and energetic density}

The results for the NCV analyzed were between 11,500 and $18,500 \mathrm{~kJ} / \mathrm{kg}$. The values obtained were similar to those found by other authors for these types of biomass (García et al., 2012). The maximum $\mathrm{CV}$ of the samples studied was for almond shells and olive tree prunings; this is related mainly to the higher carbon content present in these biomass samples. The bulk density of the biomass feedstocks affects the size and cost of the biomass storage, transport, handling and processing systems and the behavior of the biomass during thermochemical conversion. The lower the bulk density of a biomass material, the larger the transportation sizes, storage and handling equipment will have to be (Wang, 2008). The almond shell samples had the highest bulk densities, at $324.3 \mathrm{~kg} / \mathrm{m}^{3}$, while for the rest of the samples, the bulk density values obtained were equal to or less than $100 \mathrm{~kg} / \mathrm{m}^{3}$.

In addition, the energy density was calculated because this parameter takes into account not only the bulk density but also the NCV. The energy density is defined as the biomass heat value on a volumetric basis. A trend similar to that found in the values for bulk density and NCV was observed in the energy density - the almond shell samples giving the highest value out of all the biomasses studied.

\subsubsection{Elementary analysis and the chlorine and sulphur contents}

Corresponding with another biomass (Vassilev et al., 2010), the main element found in this analysis was carbon, with values greater than $31.7 \%$, and up to $50.5 \%$. Moreover, the hydrogen values obtained were similar in all cases, between $4.3 \%$ and $6.2 \%$. However, differences were found regarding the nitrogen content. Almond shells, olive tree prunings and holm oak prunings showed similar values, lower than $0.7 \%$, but the greenhouse vegetable residue samples from tomato and pepper plants presented values between $1.8 \%$ and $3.8 \%$, with the maximum value found in vegetable residues from greenhouse tomato plants. This is due to these types of biomass samples having higher protein contents.

Almond shells, olive tree prunings and holm oak prunings have low sulphur and chlorine contents, with values below $60 \mathrm{mg} / \mathrm{kg}$ for chlorine and $0.06 \%$ for sulphur. The presence of leaves in olive tree pruning samples means that this raw material has a slightly higher sulphur content (Garcia-Maraver et al., 2015). On the other hand, both greenhouse residues studied had high chlorine and sulphur contents, close to the values reported in the literature (García et al., 2012). High values for these elements (AENOR, 2014b) are due to agricultural activities using inorganic additives containing sulphur and water in coastal areas; this is rich in $\mathrm{NaCl}$ (AENOR, 2014a), as is the case in the Almería area, from where the vegetable residues were taken.

\subsubsection{Solid biofuel standard}

For some of the biomass studied in this work, standards have already been developed by a technical standardization committee, which classified them according to their energy parameters. In this way, biomass can be classified as solid biofuel of greater or lesser quality for bioenergy applications.

Specifically, for almond shells, when comparing the values obtained in the energy analysis with the (AENOR, 2014b) specifications, the NCV, sulphur and chlorine contents would be in the maximum category, class A1. On the other hand, both the bulk density and the ash content would correspond to class A2, whilst the moisture, which was slightly higher than $12 \%$, would correspond to the third class, B. This moisture content could be reduced by introducing a drying step prior to utilizing the biomass for bioenergy applications.

With regard to the olive tree prunings and holm oak prunings, according to (AENOR, 2014c) the graded firewood analysis corresponds to class A2. In addition, for chips of this type of biomass, the ISO 172254 standard regarding wood chips, indicates that all the parameters obtained for both olive and holm oak prunings would correspond to class A2; except for the ash content, which was slightly above $3 \%$ in both cases. For the woody biomass variations of the ash content, this may be due to the presence of bark in the wood (AENOR, 2014a).

\subsection{Biomass availability}

The agronomic analysis considered the areas cultivated and the biomass production generated. Table 3 shows the hectares of biomass production considered in the study. Almond, olive, oak, and tomato and pepper plantations in greenhouses, were the crops analyzed. It was concluded that holm oak is a nonexistent crops within a $100 \mathrm{~km}$ radius 
Table 3

Hectares of biomass cultivation and production considered in Almería.

\begin{tabular}{lll}
\hline Biomass & Production (ha) & Production (t/year) \\
\hline Almond & $73,965^{* *}$ & 5,323 \\
Olive & $19,360^{* * *}$ & 58,080 \\
Holm oak & & \\
Tomato plantations in greenhouses & $10,300^{* * * * *}$ & 755,000 \\
Pepper plantations in greenhouses & $8,779^{* * * *}$ & 324,000 \\
\hline
\end{tabular}

* (Consejería de Agricultura y Pesca, Junta de Andalucía, 2011).

** (Consejería de Agricultura y Pesca, Junta de Andalucía, 2013).

*** (Consejería de agricultura, pesca y desarrollo rural, Junta de Andalucía, 2016).

of the location under study. The largest number of hectares planted were for tomato plantations in greenhouses followed by almonds and olives, and finally greenhouse pepper plantations. The estimated tonnage produced annually from biomass is also summarized in Table 3. Greenhouse vegetable residues from tomatoes and peppers represented the highest tonnage while almond shells had the lowest values. In principle, a secure supply cannot be guaranteed since the power of plant and the mode of operation condition the needs.

The equivalent hours of operation (the theoretical annual hours of operation) of the plant are dependent on the amount of available biomass; this determines whether or not the plant can be fed with the amount of resource available, as indicated in Table 4. To calculate the equivalent hours, equations (5) and (6) were used, where the gasifier, the product gas boiler, the power cycle and the alternator were considered as having values of $0.6,0.8,0.3$ and 0.98 . The most optimal results for the equivalent hours of operation determine that, for olive tree prunings, it would be possible to operate the plant annually at full load for $8,760 \mathrm{~h}$, day and night, without exhausting the available biomass resource. In contrast, for the almond shells, it would be necessary to carry out good biomass management throughout the year so as to avoid supply problems, or to consider using two biomass resources to feed the plant. Greenhouse vegetable residues from tomato and pepper plants could provide the capacity to operate the plant at full load (and even at energy levels much greater than the one we considered); however, this fact is counteracted by the corresponding technical data. Finally, holm oak prunings were not considered as they were not available within the $100 \mathrm{~km}$ radius around the solar thermal energy hybrid plant location.

$\eta_{t}=\eta_{\text {gasif }} * \eta_{c, \text { syngas }} * \eta_{c p} * \eta_{\text {alt }}$

$H_{e q, \max }=\frac{\operatorname{Prod}_{b i o} * N C V_{b i o} * \eta_{t}}{P_{e}}$

The most optimal results for the equivalent hours of operation determine that, for olive tree prunings, it would be possible to operate the plant annually at full load for $8,760 \mathrm{~h}$, day and night, without exhausting the available biomass resource. In contrast, for the almond shells, it would be necessary to carry out good biomass management throughout the year so as to avoid supply problems, or to consider using two biomass resources to feed the plant. Greenhouse vegetable residues from tomato and pepper plants could provide the capacity to operate the plant at full load (and even at energy levels much greater than the

Table 4

Equivalent hours of production.

\begin{tabular}{ll}
\hline$H_{\text {eq, } \max }$ & \\
\hline Almond shells & 3,854 \\
Olive tree prunings & 35,715 \\
Holm oak prunings & 0 \\
Greenhouse vegetable residues from tomato plants & 341,212 \\
Greenhouse vegetable residues from pepper plants & 196,481
\end{tabular}

Table 5

Summary of biomass costs. 2013 Annuity.

\begin{tabular}{ll}
\hline Biomass & Cost $(€ / \mathrm{kg})$ \\
\hline Almond shells & $0.07^{\mathrm{a}}$ \\
Olive tree prunings & $0.04^{\mathrm{a}}$ \\
Greenhouse vegetable residues from tomato plants & $0.01^{\mathrm{b}}$ \\
Greenhouse vegetable residues from pepper plants & $0.01^{\mathrm{b}}$ \\
\hline
\end{tabular}

a Estimated data through surveys to companies in the almond sector during the 2013 annuity.

b (Excmo. Ayundamiento de El Ejido, Área de Hacienda y Contratación, 2014).

one we considered); however, this fact is counteracted by the corresponding technical data. Finally, holm oak prunings were not considered as they were not available within the $100 \mathrm{~km}$ radius around the solar thermal energy hybrid plant location.

\subsection{Cost}

To collect the economic data, several premises were considered: a) based on logistic-economic considerations, the study region was limited to a maximum $100 \mathrm{~km}$ radius and $\mathrm{b}$ ) the cost of the biomass was per kilogram and based on it being untreated. It is important to note the annual price variability and the data considered correspond to the annuity for 2013. Table 5 shows the costs of each biomass type per kilogram; these data are an estimate based on the data obtained after consulting on prices from different companies, while the prices for greenhouse vegetable residues from tomato and pepper plants are the minimum paid by farmers to authorized companies for collection and management.

In conclusion, the most favorable data from the economic point of view are for greenhouse vegetable residues from tomato and pepper plants - this fact, however, is counteracted by the physical, chemical and energetic properties, which are not very favorable in terms of energy recovery through gasification. Conversely, the almond shells and olive tree prunings present a considerable cost: at 0.07 and $0.04 € / \mathrm{kg}$, respectively, but they possess very good technical qualities for possible energy recovery, without needing pretreatment.

\subsection{Final multicriteria selection}

For the final decision-making step on the biomass resources used in a FBG process incorporated into a STE hybrid, all the information collected and calculated throughout the article was utilized. This was evaluated in a multicriteria analysis using the Visual PROMETHEE toolGeometrical analysis for interactive aid (GAIA). PROMETHEE is designed to classify objects whereas GAIA is a related visualization method which provides a guide for identifying variables. The four biomass resource alternatives were considered by comparing them against the three criteria: technical $(64.3 \%)$ with a greater weight due to the fact that pre-treatments were not carried out before, therefore it is necessary to have the best possible quality, logistic-agronomic $(14.3 \%)$ with a lower weight since it has been considered a location of the plant in an area where a large amount of biomass are available and economic $(21.4 \%)$ with a medium weight due to the typology of the studies since if they were at an industrial level, a greater weight should be considered. Regarding the criteria weighting, for the technical criterion, this was carried out using a filter determining whether or not the biomass properties were suitable for consideration without performing any pre-treatment. For the economic and logistic-agronomic criteria, these were weighted according to five levels (very good, good, medium, bad or very bad).

Fig. 1 shows the graphical results of the multivariate analysis using the GAIA visualization. Three optimal points are shown for each criterion in blue and the average optimum point in red. For the five 


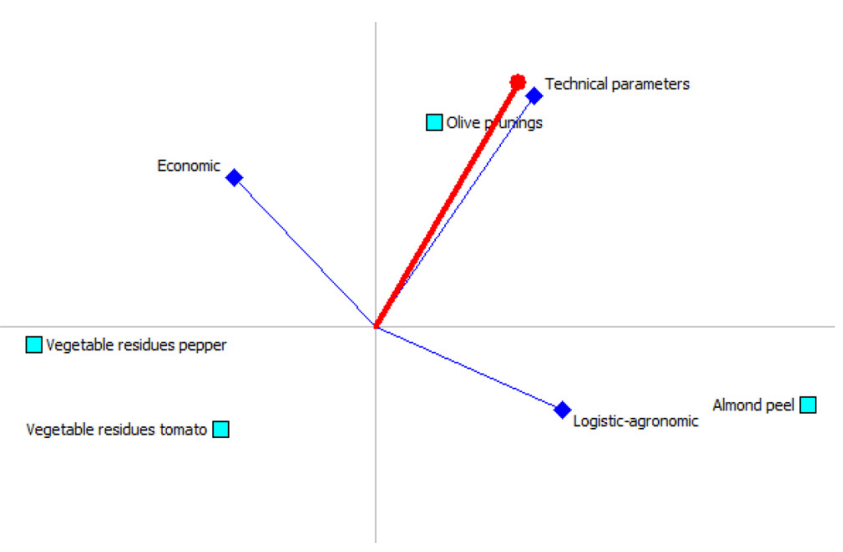

Fig. 1. GAIA visual analysis.

biomass resources considered, one can observe that the olive tree prunings most closely approach the optimum point (determined by PROMETHEE-GAIA), making them the best option to consider.

\section{Conclusion}

From the technical point of view, the best biomass resource to consider are almond shells because of their excellent technical parameters, good GCV value $(19,822 \mathrm{~kJ} / \mathrm{kg}$ ), low sulphur (below $0.06 \%$ ) and chlorine contents (below $60 \mathrm{mg} / \mathrm{kg}$ ) - meaning that this biomass can be classified as category A1 according to the UNE 164004 standard. Considering their acceptable bulk density $\left(324.3 \mathrm{~kg} / \mathrm{m}^{3}\right)$ and ash content $(1.1 \%)$ parameter values, almond shells would be classified as type A2 biomass, whereas their slightly higher humidity (12\%) value would classify almond shells as type B. Both olive tree prunings and holm oak prunings are biomass resources with good characteristics, which according to ISO 17225-5 on firewood classification, would be considered as category A2. On the other hand, if one rates them according to the
17225-5 standard on chippings, they could also be classified as type A2 apart from their moisture level (3\%), which is a slightly higher value.

Greenhouse vegetable residues from tomato and pepper plants are biomass resources that, until now, have not been revalued to a large extent, and do not have a standard allowing classification according to their technical parameters, considering in these works the technology of exploitation which check whether the technical parameter is suitable or not. In terms of their humidity, ash and sulphur contents, the high values could have negative consequences when developing the gasification process, such as corrosion and fouling of the different components. Another parameter that has an undesirable value is the $\mathrm{CV}$, which is low for its energy use. In addition, the heterogeneity of this biomass must be taken into account, assuming an added level of complexity.

With regard to the economic factor, the best costs are for vegetable residues $(0.01 € / \mathrm{kg})$, which is the price paid by the farmer to the waste manager, compared to almond shells, which have a very high cost $(0.07 € / \mathrm{kg})$.

Finally, the logistic-economic factor, which has a lesser weighting, considered a radius of $100 \mathrm{~km}$ around the solar thermal energy hybrid plant location together with the annual production of the different biomass resources, thus determining the theoretical hours of production in the plant - in the case of almond shells, this resulted in 3854 equivalent hours, which would not allow full-load operation $24 \mathrm{~h}$ a day. In comparison, this could be done for the other biomass resources because they exceeded $8,760 \mathrm{~h}$ a year. This fact reflects the importance of choosing a mode of operation that allows adequate resource manageability.

The choice of biomass resource, based on the different criteria, was supported by a multicriteria analysis using the Visual-PROMETHEE-GAIA tool, which, after weighting the different criteria, defined an optimum point. The closer the proximity of the biomass to this point, the more suitable its use in a FBG process incorporated into a solar thermal energy hybrid plant. The biomass resource that was closest to this optimal point was olive tree prunings.

\section{Appendix A. Meaning equations parameters}

\begin{tabular}{|c|c|}
\hline Symbols & Meaning \\
\hline & $M_{a r}=$ moisture (equation 1) \\
\hline $\mathrm{M}_{\mathrm{ar}}$ & Moisture content as the sample is received \\
\hline $\mathrm{m}_{1}$ & Mass of the empty tray, $g$ \\
\hline $\mathrm{m}_{2}$ & Mass of the tray and the sample before drying, $g$ \\
\hline $\mathrm{m}_{3}$ & Mass of the tray and the sample after drying, $g$ \\
\hline $\mathrm{m}_{4}$ & Mass of the reference tray before drying (weight at room temperature), $g$ \\
\hline $\mathrm{m}_{5}$ & Mass of the reference tray after drying (weight when it is still hot), $g$ \\
\hline \multirow[t]{2}{*}{$\mathrm{m}_{6}$} & Mass of the packing moisture, $\mathrm{g}$ \\
\hline & $A_{d}=$ ashes (equation 2) \\
\hline$A_{d}$ & Ash content of the sample on a dry basis \\
\hline $\mathrm{m}_{1}$ & Mass of the empty crucible, $g$ \\
\hline $\mathrm{m}_{2}$ & Mass of the crucible together with the sample before introducing it into the oven, $g$ \\
\hline $\mathrm{m}_{3}$ & Mass of the crucible and ash, $g$ \\
\hline \multirow[t]{2}{*}{$\mathrm{M}_{\mathrm{ad}}$} & Percentage of moisture content in the milled sample used for the determination (UNE-EN 14774-3:2010) \\
\hline & $V_{d}=$ volatile matter (equation 3 ) \\
\hline $\mathrm{V}_{\mathrm{d}}$ & Volatile content of the sample on a dry basis \\
\hline $\mathrm{m}_{1}$ & Mass of the empty crucible and its lid, $g$ \\
\hline $\mathrm{m}_{2}$ & Mass of the crucible, its lid and its contents before heating, $g$ \\
\hline $\mathrm{m}_{3}$ & Mass of the crucible, its lid and its contents after heating, $g$ \\
\hline $\mathrm{M}_{\mathrm{ad}}$ & $\begin{array}{l}\text { Percentage of moisture contained in the milled sample used for the determination (UNE-EN 14774-3:2010) } \\
\qquad Q_{p, n e t, d}=\text { net calorific value (equation 4) }\end{array}$ \\
\hline $\mathrm{q} v, \mathrm{gr}, \mathrm{d}$ & Gross calorific value at constant volume of dry fuel (without moisture), $\mathrm{J} / \mathrm{g}$ \\
\hline $\mathrm{H}_{\mathrm{A}}$ & Content of hydrogen, in percentage of mass, of the biofuel without moisture \\
\hline $\mathrm{O}_{\mathrm{A}}$ & Oxygen content, in percentage of mass, of the biofuel without moisture \\
\hline $\mathrm{N}_{\mathrm{A}}$ & $\begin{array}{l}\text { Nitrogen content, in percentage of mass, of the biofuel without moisture } \\
\qquad \eta_{t}=\text { total efficiency of the plant (equation 5) }\end{array}$ \\
\hline$\eta_{\text {gasif }}$ & Gasifier efficiency \\
\hline$\eta_{c, \text { syngas }}$ & Efficiency of the gas boiler product \\
\hline$\eta_{c p}$ & Power cycle efficiency \\
\hline$\eta_{\text {alt }}$ & Alternator efficiency \\
\hline & $H_{\text {eq, } \max }=$ equivalent hours (equation 6) \\
\hline
\end{tabular}




$\begin{array}{ll}\operatorname{Prod}_{\text {bio }} & \text { Production of annual biomass in the province of Almería } \\ N C V_{\text {bio }} & \text { Lower calorific value of the biomass (kJ/kg on a dry basis) } \\ \eta_{t} & \text { Total efficiency of the plant } \\ P_{e} & \text { Nominal electric power of the plant }\end{array}$

\section{References}

AENOR, 2014a. In: AENOR (Ed.), EN ISO 17225-1, Solid biofuels-Fuels specifications and classes- Part 1: General requirements. AENOR, Madrid (AENOR).

AENOR, 2014b. In: AENOR (Ed.), UNE 164004:2014, Biocombustibles sólidos-especificaciones y clases de combustibles-cáscaras de frutos. AENOR, Madrid (AENOR).

AENOR, 2014c. In: AENOR (Ed.), UNE EN ISO 17225-5, Solids biofuels-Fuel specifications and classe-Part 5: graded wood chips. AENOR, Madrid (AENOR).

Andalusian Agency of Energy, 2016. Datos energéticos de andalucía 2016. In: C. y E. (Agencia A. de la E. Consejeria de Innovación (Ed.), Sevilla: Consejeria de Innovación, Ciencia y Empresa (Agencia Andaluza de la Energía), Retrieved from. https://www.agenciaandaluzadelaenergia.es/sites/default/files/documentos/datos energeticos_andalucia_2016.pdf.

Díaz, M.J., Huijgen, W.J.J., Van Der Laan, R.R., Reith, J.H., Cara, C., Castro, E., 2011. Organosolv pretreatment of olive tree biomass for fermentable sugars. Holzforschung. https://doi.org/10.1515/HF.2011.030.

European biomass association. (2017). www.aebiom.org.

European Solar Thermal Electricity Association, 2012. Strategic Research Agenda 20202015. Brussels Retrieved from http://www.estelasolar.org/Docs/2012 ESTELAStrategicResearchAgenda 2020-2025_Jan2013_WEB.pdf.

García, R., Pizarro, C., Lavín, A.G., Bueno, J.L., 2012. Characterization of Spanish biomass wastes for energy use. Bioresour. Technol. https://doi.org/10.1016/j.biortech.2011. 10.004 .
Garcia-Maraver, A., Rodriguez, M.L., Serrano-Bernardo, F., Diaz, L.F., Zamorano, M., 2015. Factors affecting the quality of pellets made from residual biomass of olive trees. Fuel Process. Technol. https://doi.org/10.1016/j.fuproc.2014.08.018.

Gómez-Barea, A., Leckner, B., 2010. Gasification of biomass and waste. Handbook of Combustion. https://doi.org/10.1002/9783527628148.hoc064.

International Energy Agency, 2017. Renewables Information: Overview. Retrieved from. https://www.iea.org/publications/freepublications/publication/ RenewablesInformation2017Overview.pdf.

Kiely, G., 2003. In: Hill, M.G. (Ed.), Ingeniería Ambiental (fundamentos, entornos, tecnologías y sistemas de gestión), Madrid.

María Guadalupe Pinna Hernández, 2017. Solar-biomass hybridization in thermoelectric plant. Almería.

Ministry of Agriculture and Fisheries, F. and E. (2014). http://eportal.mapama.gob.es/ websiar/Inicio.aspx. Retrieved from http://eportal.mapama.gob.es/websiar/Inicio. aspx.

Vassilev, S.V., Baxter, D., Andersen, L.K., Vassileva, C.G., 2010. An overview of the chemical composition of biomass. Fuel. https://doi.org/10.1016/j.fuel.2009.10.022.

Wang, L., 2008. Energy efficiency and management in food processing facilities. In: CRC Press (Ed.), Thermochemical Conversion of Food Processing Wastes for Energy Utilization.

Werther, J., Saenger, M., Hartge, E.U., Ogada, T., Siagi, Z., 2000. Combustion of agricultural residues. Prog. Energy Combust. Sci. https://doi.org/10.1016/S03601285(99)00005-2. 